\title{
Injury Pattern among Road Traffic Accidents' Victims in Najran City, Saudi Arabia
}

\author{
Mahdi Yahya Al-Zamanan', Abdullah Saleh Al-Yami1, Ali Abdullah Al-Najrani1, \\ Mansour Yousef Al-Asmari'2, Abdulrahman Alamri Manaa ${ }^{2}$, Awad Mohammed Al-Qahtani' \\ Mohammed Helmy Faris Shalayel ${ }^{1}$, Abdulhadi Mohamed Elbashir ${ }^{2}$, Saeed Ali Alsareii ${ }^{2}$ \\ ${ }^{1}$ College of Medicine, Najran University, Najran, Saudi Arabia \\ ${ }^{2}$ Department of Surgery, College of Medicine, Najran University, Najran, Saudi Arabia \\ ${ }^{3}$ Department of Family and Community Medicine, College of Medicine, Najran University, Najran, Saudi Arabia \\ Email: ^drmhfs@hotmail.com
}

How to cite this paper: Al-Zamanan, M.Y., Al-Yami, A.S., Al-Najrani, A.A., Al-Asmari, M.Y., Manaa, A.A., Al-Qahtani, A.M., Shalayel, M.H.F., Elbashir, A.M. and Alsareii, S.A. (2018) Injury Pattern among Road Traffic Accidents' Victims in Najran City, Saudi Arabia. International Journal of Clinical Medicine, 9, 270-280.

https://doi.org/10.4236/ijcm.2018.94024

Received: March 19, 2018

Accepted: April 24, 2018

Published: April 27, 2018

Copyright $\odot 2018$ by authors and Scientific Research Publishing Inc. This work is licensed under the Creative Commons Attribution International License (CC BY 4.0).

http://creativecommons.org/licenses/by/4.0/

\begin{abstract}
Traffic accidents constitute the substantial cause of disability and mortality in the young Saudi individuals reaching horrible figures. The aim of this study was to review and identify the pattern of injury among road traffic accident (RTA) victims as well as the peak time of accidents and their implications. This retrospective hospital-based cross-sectional study was carried out in the period between April 2016 to March 2017 in King Khalid Hospital, Maternity and Children Hospital and Najran General Hospital, Najran, Saudi Arabia. All RTA victims admitted to the emergency departments of the pre-mentioned hospitals. Data collected from 435 Saudis and non-Saudis' files were statistically analyzed with regard to age, gender, the timing of road traffic accidents, injury pattern, and neurological deficits incidence. Most of the RTAs' cases (92\%) were male victims with the highest peak in the age group $20-29$ years. 58\% of the RTAs happened in the evening (6:00 PM-9:00 PM) while $20 \%$ occurred in the morning. Head injury represented the most frequent pattern (36\%) followed by the spinal injury (23\%), lower limb injury (23\%), upper limb injury (20\%), thoracic injury (17\%), pelvic injury and abdominal injury (8\%). $4.4 \%$ of RTAs resulted in death whilst $9 \%$ of cases experienced neurological deficits. In conclusion, young male drivers in Najran recorded the highest frequency of RTAs. Initiation of road safety education and expansion of speed detectors (Saher) system deployment is highly recommended.
\end{abstract}

\section{Keywords}

Road Traffic Accidents (RTA), Road Traffic Injuries (RTIs), Disability 


\section{Introduction}

The injuries caused by road traffic accidents (RTAs) become a major public health problem worldwide and a major cause of morbidity and mortality with temporary or permanent disability [1]. Road traffic accidents have become one of the most important disadvantageous impacts of man's interrelationship with technology [2]. There is an epidemic of road traffic accidents in Saudi Arabia that is second only to infectious disease as a medical problem. Traffic accidents represent the leading cause of death and disability in the young (16 to 36 years old). It is an epidemic as serious as plague or smallpox was to earlier generations [3].

Between 1971 and 1997; 564,762 people died or were injured in road traffic accidents In Saudi Arabia, a figure equivalent to 3.5\% of the total population in Saudi Arabia [4].

Injury was the largest single cause of disability-adjusted life years and death in the Kingdom of Saudi Arabia in 2013. The vast majority of injury-related fatalities are deaths caused by road traffic [5]. According to Saudi Arabia's Ministry of Health, injury was implicated in $18.5 \%$ of deaths within the Kingdom [6]. Soundly, road fatalities in KSA have increased over the last decade from 17.4 - 24 per 100,000 population compared with 10 in USA, and 5 in UK, where road safety has been taken seriously, and all primary and secondary preventive measures are implemented appropriately [7]. Saudi hospitals' data showed an $8 \%$ non-significant increase in road accident mortalities in contrast to police records of a $27 \%$ significant reduction during the years 2005-2010 [8].

This study aimed to review the files of victims of road traffic accidents in $\mathrm{Na}$ jran City from April 2016-March 2017 to identify the pattern of injury among road traffic accident victims. More specifically, it tried to identify the peak time of accidents and their implications.

\section{Methods}

\subsection{Study Design and Participants}

This study utilized a retrospective hospital based cross-sectional research design which included all RTA victims admitted to the emergency department in King Khalid Hospital (KKH), Maternity and Children Hospital (MCH) and Najran General Hospital (NGH). The study was carried out in the period between April 2016 to March 2017 and included 435 Saudis and non-Saudis (males and females) RTA victims in $\mathrm{KKH}, \mathrm{MCH}$ and $\mathrm{NGH}$. These hospitals provides free healthcare, including all medical procedures, medications and surgical interventions. Patients are received by emergency departments of these hospitals containing specialized teams including emergency physicians and orthopedic surgeons.

In accordance with The Saudi Trauma Registry that initiated in 2001 [9], An injured patient must meet at least one of the following criteria to be included: 1) admission to the hospital ward or intensive care unit from the emergency de- 
partment (ED); 2) transfer to urgent surgery from the ED; 3) indirect admission (patient discharged from ED and asked to return later); or 4) death after arrival to the ED.

Data were extracted from hospitals' information system file and entered into the data extraction sheet. Data included nationality, age, gender, time of occurrence of road traffic accidents, injury pattern, Injury Severity Score (ISS), and neurological deficits occurrence. Collected data were then statistically analyzed using SPSS program.

\subsection{Ethical Review}

This study was reviewed and approved by Deanship of Scientific Research (DSR-NU), Najran University, Saudi Arabia. DSR-NU approved conduct of the research without explicit consent from the participants.

\subsection{Statistical Analysis}

Patients were compared on the following variables: age, sex, Time of accident, Injury Severity Score (ISS), and injury pattern. The following variables were included in the multivariable analysis: age, sex, ISS, and injury pattern. Logistic regression analysis was carried out to determine the odds of in-hospital predictors based on these variables.

\section{Results}

Our results showed that that $58 \%$ of the RTAs happened in the evening (6:00 PM-9:00 PM), 22\% happened at night (beyond 9 PM), and only $20 \%$ of the cases happened in the morning. $69 \%$ of victims were Saudis whereas, $31 \%$ were non-Saudis. Most of the RTAs' cases (92\%) were male victims and only $8 \%$ of cases were females. Estimated percentages and Odds Ratios (OR) with $95 \%$ confidence intervals (CI) from a multivariable logistic regression of in-hospital predictors are shown in Table 1.

The highest incidence of RTAs was found in the age group 20 - 29 years old whereas the lowest one was seen in the age group $\geq 70$ years old. Ages' distribution of victims is shown in Figure 1.

The most frequent form of injury was head injury which represented $36 \%$ of cases while spinal injury, lower limb injury, upper limb injury, thoracic injury, pelvic injury and abdominal injury recorded 23\%,23\%,20\%,17\%, $8 \%$ and $8 \%$ of cases respectively (Figure 2). With respect to neurological implication, it was found that $9 \%$ of cases experienced neurological deficits while $91 \%$ of cases were not affected.

Our study also revealed that $4.4 \%$ of RTAs' cases died either on spot or in the hospital.

\section{Discussion}

As the fatality on road traffic accidents could become the fifth substantial cause 
Table 1. Estimated percentages and Odds Ratios (OR) with 95\% confidence intervals (CI) from a multivariable logistic regression of in-hospital predictors including deaths $(\mathrm{n}=$ 435).

\begin{tabular}{|c|c|c|}
\hline Variables & $\%$ & OR $(95 \% \mathrm{CI})$ \\
\hline \multicolumn{3}{|l|}{ Age category } \\
\hline 1 - 9 years & 3 & $0.032(0.006-0.67)$ \\
\hline 10 - 19 years & 24 & $0.315(0.062-5.99)$ \\
\hline $20-29$ years & 34 & $0.516(0.102-6.16)$ \\
\hline $30-39$ years & 23 & $0.30(0.059-5.19)$ \\
\hline $40-49$ years & 9 & $0.10(0.019-1.09)$ \\
\hline $50-59$ years & 5 & $0.054(0.011-2.81)$ \\
\hline $60-69$ years & 1 & $0.0128(0.002-0.70)$ \\
\hline$\geq 70$ years & 1 & $0.0104(0.002-0.59)$ \\
\hline \multicolumn{3}{|l|}{ Gender } \\
\hline Males & 92 & $0.92(0.18-1.46)$ \\
\hline Females & 8 & $0.089(0.02-0.54)$ \\
\hline \multicolumn{3}{|l|}{ Time of accident } \\
\hline Morning & 20 & $0.25(0.05-2.74)$ \\
\hline Evening & 22 & $0.28(0.06-4.42)$ \\
\hline At night & 58 & $1.38(0.03-9.67)$ \\
\hline \multicolumn{3}{|l|}{ ISS category } \\
\hline $0-9$ & 50 & $0.99(0.7-3.2)$ \\
\hline $10-24$ & 24 & $0.49(0.2-1.9)$ \\
\hline $25-44$ & 21 & $0.43(0.18-2.1)$ \\
\hline $45-75$ & 5 & $0.05(0.03-1.42)$ \\
\hline \multicolumn{3}{|l|}{ Injury pattern } \\
\hline Head & 36 & $0.56(0.01-8.36)$ \\
\hline Spinal & 23 & $0.32(0.06-1.19)$ \\
\hline Lower limb & 23 & $0.31(0.07-1.17)$ \\
\hline Upper limb & 20 & $0.25(0.07-2.63)$ \\
\hline Thoracic & 17 & $0.20(0.04-1.30)$ \\
\hline Pelvic & 8 & $0.09(0.017-4.54)$ \\
\hline Abdominal & 8 & $0.088(0.015-4.45)$ \\
\hline
\end{tabular}

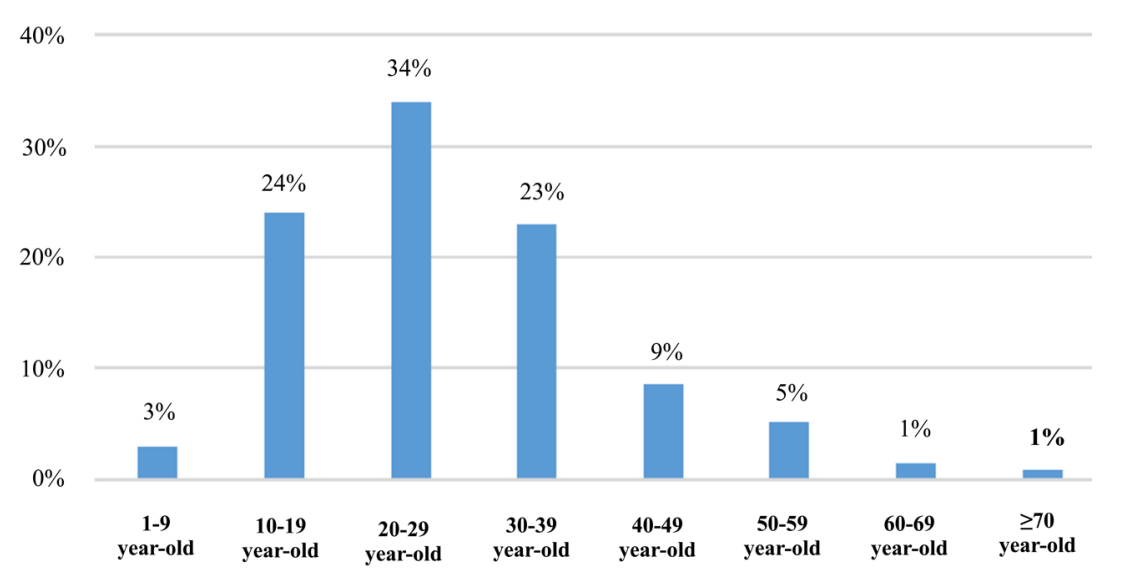

Figure 1. Ages' distribution of RTAs victims in Najran (April 2016-March 2017). 


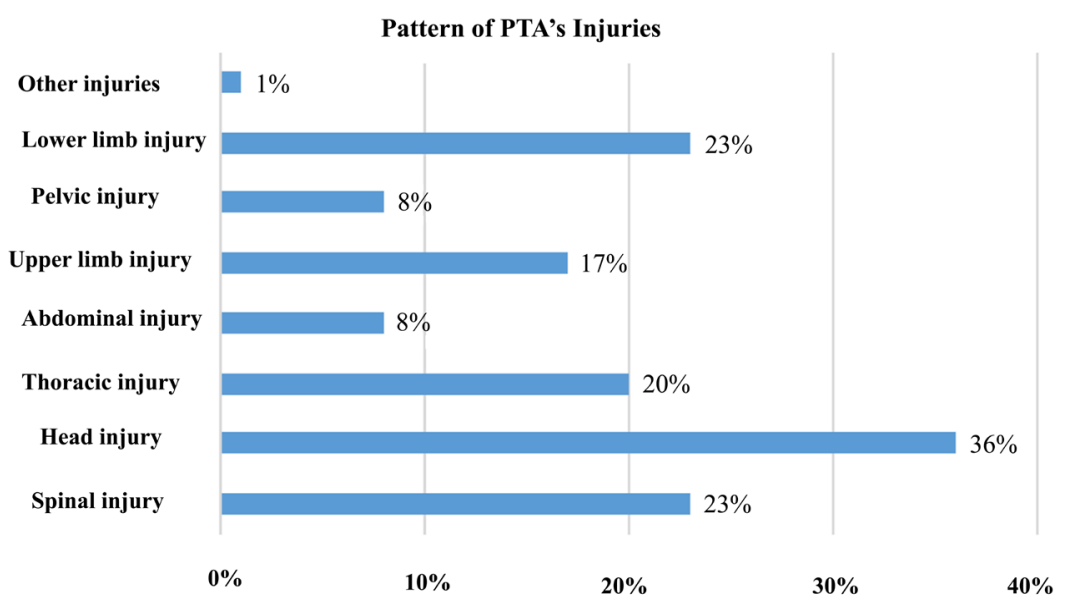

Figure 2. Pattern of RTAs injuries.

of death in 2030, the WHO initiated the "Decade of Action for Road Safety" [10]. Thus implementation of effective strategy is necessary in Saudi Arabia where motor vehicles kill one person and injure 4 ones every hour [11].

With the unprecedented cases of road traffic accidents across the world, the need to identify pattern of injuries has become radical with hope that data generated can improve behavioral risk and road traffic policies. It is this hope that our survey was conducted.

Looking at the data of traffic accidents and casualties from 2013-2015 among the regions of Saudi Arabia would justify the magnitude of RTAs problem. Road injuries were stated to be the most earnest problem there with an accident to injury ratio of 8:6, equiponderated with the international ratio of 8:1 [4] with highest RTAs occurrence in Riyadh, Jeddah, Makkah, Madinah, and Qassim [8]. Hence, According to the morbidity and mortality records in the Ministry of Health (MOH) hospitals, $20 \%$ of beds are occupied by RTA victims, and $81 \%$ of deaths in the hospitals are due to RTIs [4].

In 2016, the number of accidents raised by $2.8 \%$ compared to 2015 according to data of the General Authority for Statistics and the Ministry of Municipal and Rural Affairs [12]. There are many global risk factors for RTAs as reported by WHO including speeding, driving under the effect of psychoactive substances, Nonuse of seatbelt, hamlets and child restraints, distracted driving caused by mobile phones, unsafe vehicles and road infrastructure, insufficient post-crash care, and inadequate law enforcement of traffic laws [13].

The result of our study with respect to timing showed that $58 \%$ of the RTAs happened in the evening (6:00 PM-9:00 PM) and 20\% happened in the morning. These findings are comparable with many other national and worldwide studies. Batouk et al. reported that peak number of RTAs cases (38\%) were seen during the daylight hours between 12:00 and 18:00 hours [14]. Similarly, Schlottmann et al. reported that $67 \%$ of collisions in Malawi occurred at daylight, $32 \%$ occurred at night and $0.8 \%$ occurred at dawn [15]. Concordantly, Khan and his colleagues reported that maximal incidence of road traffic accidents occurred during 2.00 
PM to 5.00 PM [16].

A study in Western Nepal showed that the maximum number of accidents (44.16\%) occurred between 3 and 7 PM followed by that between 7 and $11 \mathrm{AM}$ (24.16\%). Mortality wise, highest number of cases was found between 3 and 11 PM (72.72\%). The distributions of non-fatal cases were maximum from 3 to 7 PM (44.89\%) [17]. Many other studies in India found that the sublime number of casualties happened roughly between 12-8 PM [18] [19].

Daytime is the customary working time in Saudi Arabia for institutions, schools and governmental and private offices so there is a vast number of vehicles at this time along with 6-9 PM which represents time for getting back from work or going for shopping, entertainment, attending either family or religious responsibilities that drivers would tend to speed up to catch up with those activities. Consequently, much more vehicles are present on the road during this rush hour. Other studies pointed out that this also represents the period during which people are engaged in outdoor recreational activities [20] [21]. Nevertheless, just $20 \%$ of RTAs were reported during the day in Najran area were drivers may be are more cautious to obey traffic regulations. Our results were not in homology with that obtained from Qassim where $51.2 \%$ of the cases occurred during the day while the rest occurred at night [4].

With respect to gender and age affection, most of the RTAs' cases in our study (92\%) were male victims with the highest incidence in the age group $20-29$ years, the most adventurous age. This is logic in Najran and coincides with many previous studies in Saudi Arabia and even worldwide. Since the drivers here in Saudi Arabia are only males, male victims are mostly vulnerable to RTAs. Similar figures were reported in Jazan (Saudi Arabia) where approximately half of trauma patients were in the age of $18-30$ years $(25.3 \pm 16.8$ years, mean \pm S.D) with male ascendancy (64.3\%) [22] and in Arar (Northern Saudi Arabia) where RTAs occurring frequently with young persons aged less than 35 years old (70.8\%) [23].

Gender difference in our country is self-explanatory for local prevalent driving laws. Young aged drivers are more affected in KSA utilizing cars for amusement rather than purposes [24].

An analysis of percentages and frequencies of the traffic accident fatalities in Ecuador revealed that out of 1976 fatalities registered in 2016, 81.1\% corresponded to men and $18 \%$ to women and the deceased groups between the ages of $0-17$ and 18 - 24 correspond in the first case to pedestrians and in the second case as young inexperienced drivers mainly due to the lack of road education and the scarce individual risk perception tied to their age as road users [25]. A Libyan study reported that massive majority of the RTAs victims ( $80.5 \%$ among surviving victims and $88.5 \%$ among those who died) were males and the most common age group affected in the study was between 21 and 40 years [26]. Similar results were reported in Kuwait [27]. In a recent study conducted in Malawi, A total of 11,467 RTCs were reported by the Malawian National Road Safety 
Council Registry between 2008 and 2012. The average age of victims was 32 years and $88 \%$ were male. Of these, $34 \%$ involved at least one fatality on spot [15].

A prospective hospital based study was conducted to assess outcome and injury characteristics of road traffic accident among victims at Adult Emergency Department of Tikur Anbessa specialized hospital, Addis Ababa (Ethiopia). The majority of the study subjects were men (71.7\%) and the male/female ratio was 2.6:1 with ages' mean of $32.15 \pm 14.38$ years [28].

In a Korean study, young males were reported to be influenced more than females with an increased ratio of 4:1 found in previous studies [29]. Similarly, males comprised $72.86 \%$ of facial injury patients due RTAs in an Australian study with an average age of 30.4 years [30]. Congruently, in a Colombian study, males reported more risky driving behaviors and crash involvement due to speeding violations [31].

An audit of RTAs in Saudi Arabia more than 20 years ago revealed that $16 \%$ were less than 10 years and $47 \%$ between 11 and 30 years. Male to female ratio was 4:1 reverberating the driving laws and regulations in Saudi Arabia. Burst tyres due to intense heat resulted from high speed were specified as a rife cause (39\%) of accidents [32]. In Qassim (Saudi Arabia), the rate for non-fatal RTAs in one study was higher in the 10 - 19 years age group (17.3\%) whereas, $32.95 \%$ of the cases occurred among age group 18 - 30 years old. Males had twice or more incidence rate for RTA necessitating recovery period of $\leq 7$ days as compared with females. The over exemplification of males and young adults has been reported in many studies and is possibly associated with their differential exposure to adventurous attitudes [33].

Thence, results of our study are in agreement with some previous studies in Saudi Arabia. RTA is a national public health concern which may impact Saudi's economy. In Najran Region, our data revealed that amongst road traffic injuries (RTI), head injury represented $36 \%$ of cases, followed by lower limb and spinal injury (23\% for each). Meanwhile, neurological deficits were found in $9 \%$ of cases and death occurred in $4.4 \%$ of cases. This is accordant with to a study in Al-Madinah Al-Munawwarah, Kingdom of Saudi Arabia, where the most frequently injured body regions were head and neck, followed by upper and lower extremities [8]. This may be explained by the fact that most of drivers are not restricted with safety belts hence their heads are more vulnerable to trauma. A study in Qassim reported similar results [33]. However, these results are inconsistent with an international study which reported that commonest sites abrasion injury happened in the lower limbs (34.44\%), upper limbs (28.66\%) and face (17.58 whilst lacerations were common on face $(29.69 \%)$, head $(28 \%)$ and lower limbs (24.36\%). Multiple superficial injuries were collective on lower limbs (37.14\%) and face (32.85\%) [34] [35] [36]. These figures did not specifically vary from another study in Arar (Saudi Arabia) which reported incidence of $35.1 \%$ of RTI in limbs, $32.4 \%$ in head and neck, $10.6 \%$ in chest, $3.9 \%$ in abdomen and 
17.9\% in other sites [23]. Moreover, a study in Northern Iran reported that frequency of affected anatomical body regions after RTAs were upper extremities (34.3\%), head and neck (26.4\%), lower extremities (23.5\%), face (6.4\%), Abdomen and pelvis (5.4\%), and vertebral column (3.2\%) respectively [37]. Findings of RTAs pattern is slightly different in another study in Karachi in which, the frequency of patients who had lower limb injuries was $44.7 \%$, followed by head and neck injuries (27.8\%), multiple injuries (16.1\%), upper limb injuries (5.7\%), abdominoperineal injuries (5\%), and chest injuries (0.8\%) [38]. Different figures were also reported in Nigerian study in which head and neck affection constituted $40.0 \%$ while lower limb constituted $29.0 \%$ [39].

Different pattern and figures of the affected anatomical body regions could be influenced by non-compliance with safety belts, sites of vehicle-vehicle, vehicle-fixed object and vehicle-pedestrian collisions as well as locations of vehicles' occupants.

To the best of our knowledge, it is the first study in Najran tried to identify the pattern of injury among road traffic accident victims as well as the peak time of accidents and their implications.

\section{Conclusions}

Young male drivers in Najran recorded the highest frequency of RTAs' victims with $58 \%$ of the RTAs happened in the evening. Amongst road traffic injuries (RTI), head injury represented $36 \%$ of cases, followed by lower limb and spinal injury (23\% for each) with neurological deficits occurred in $8 \%$ of cases.

Since RTI are a major health problem in Saudi Arabia which negatively impact national economy, studying pattern of road traffic injuries is a useful tool to focus on and identify the causes of RTAs. Our study has some limitations as being conducted in just 3 hospitals and did not involve all hospitals in Najran city. Although our study did not focus on the causes of RTAs, it is important to minimize them by enhancing law enforcement of traffic policies. Regulations regarding driving license release as well as license renewal should be promoted with adoption of psychophysiological tests along with initiation of road safety education and expansion of Saher system (road camera surveillance) deployment.

\section{Financial Support and Sponsorship}

Nil.

\section{Conflicts of Interest}

There are no conflicts of interest.

\section{References}

[1] Onyemaechi, N. and Ofoma, U.R. (2016) The Public Health Threat of Road Traffic Accidents in Nigeria: A Call to Action. Annals of Medical and Health Sciences Re- 
search, 6, 199-204. https://doi.org/10.4103/amhsr.amhsr_452_15

[2] World Health Organization (WHO) (2002) Violence and Injury Prevention. The Injury Chart Book: A Graphical Overview of the Global Burden of Injuries. Geneva. http://www.who.int/violence_injury_prevention/publications/other_injury/chartb/en/

[3] Al-Rodhan, N. and Lifeso, R.M. (1986) Traffic Accidents in Saudi Arabia: An Epidemic. Annals of Saudi Medicine, 6, 69-70. https://doi.org/10.5144/0256-4947.1986.69

[4] Ansari, S., Akhdar, F., Mandoorah, M. and Moutaery, K. (2000) Causes and Effects of Road Traffic Accidents in Saudi Arabia. Public Health, 114, 37-39. https://doi.org/10.1016/S0033-3506(00)00306-1

[5] DeNicola, E., Aburizaize, O.S., Siddique, A., Khwaja, H. and Carpenter, D.O. (2016) Road Traffic Injury as a Major Public Health Issue in the Kingdom of Saudi Arabia: A Review. Frontiers in Public Health, 4, 215. https://doi.org/10.3389/fpubh.2016.00215

[6] Kingdom of Saudi Arabia, Ministry of Health (2010) Health Statistical Year Book 1431. https://www.moh.gov.sa/Portal/WhatsNew/Documents/1431.pdf

[7] World Health Organization (2013) Global Status Report on Road Safety 2013. World Health Organization, Geneva. http://www.who.int/violence_injury_prevention/road_safety_status/2013/en

[8] Mansuri, F.A., Al-Zalabani, A.H., Zalat, M.M. and Qabshawi, R.I. (2015) Road Safety and Road Traffic Accidents in Saudi Arabia: A Systematic Review of Existing Evidence. Saudi Medical Journal, 36, 418-424. https://doi.org/10.15537/smj.2015.4.10003

[9] Alghnam, S., Palta, M., Hamedani, A., Remington, P.L., Alkelya, M., Albedah, K., et al. (2014) In-Hospital Mortality among Patients Injured in Motor Vehicle Crashes in a Saudi Arabian Hospital Relative to Large US Trauma Centers. Injury Epidemiology, 1, 21. https://doi.org/10.1186/s40621-014-0021-4

[10] Ernstberger, A., Joeris, A., Daigl, M., Kiss, M., Angerpointner, K., Nerlich, M. and Schmucker, U. (2015) Decrease of Morbidity in Road Traffic Accidents in a High Income Country-An Analysis of 24,405 Accidents in a 21-Year Period. Injury, 46, S135-S143. https://doi.org/10.1016/S0020-1383(15)30033-4

[11] Al Turki, Y.A. (2014) How Can Saudi Arabia Use the Decade of Action for Road Safety to Catalyse Road Traffic Injury Prevention Policy and Interventions? International Journal of Injury Control and Safety Promotion, 21, 397-402. https://doi.org/10.1080/17457300.2013.833943

[12] OVER 9,000 KILLED IN CAR ACCIDENTS IN SAUDI ARABIA IN 2016. http://www.petrolheadarabia.com/single-post/2017/05/25/

[13] World Health Organization, WHO (2017) Road Traffic Injuries. Fact Sheet. http://www.who.int/mediacentre/factsheets/fs358/en/

[14] Batouk, A.N., Abu-Eisheh, N., Abu-Eshy, S., Al-Shehri, M., Ai-Naami, M. and Jastaniah, S. (1996) Analysis of 303 Road Traffic Accident Victims Seen Dead on Arrival at Emergency Room-Assir Central Hospital. Journal of Family and Community Medicine, 3, 29-34.

[15] Schlottmann, F., Tyson, A.F., Cairns, B.A., Varela, C. and Charles, A.G. (2017) Road Traffic Collisions in Malawi: Trends and Patterns of Mortality on Scene. Malawi Medical Journal, 29, 301-305. https://doi.org/10.4314/mmj.v29i4.4

[16] Khan, Z.U., Al Asiri, K.M. and Iqbal, J. (2010) Injury Patterns from Road Traffic Accidents. Pakistan Journal of Medical Sciences, 26, 394-397. 
[17] Mishra, B., Mishra, N.D.S., Sukhla, S.K. and Sinha, A.K. (2010) Epidemiological Study of Road Traffic Accident Cases from Western Nepal. Indian Journal of Community Medicine, 35, 115-121. https://doi.org/10.4103/0970-0218.62568

[18] Singh, D., Singh, S.P., Kumaran, M. and Goel, S. (2016) Epidemiology of Road Traffic Accident Deaths in Children in Chandigarh Zone of North West India. Egyptian Journal of Forensic Sciences, 6, 255-260. https://doi.org/10.1016/j.ejfs.2015.01.008

[19] Patel, D.J. and Agnihotram, G. (2010) Study of Road Traffic Accidental Deaths (RTA) in and around Bastar Region of Chhattisgarh. Journal of Indian Academy of Forensic Medicine, 32, 110-112.

[20] Gharaibeh, E.S. and Abu Abdo, A.M. (2011) Assessment of Traffic Safety and Awareness among Youth in Al-Ahsa Region, Saudi Arabia. Journal of Emerging Trends in Engineering and Applied Sciences, 2, 210-215.

[21] Gaffar, U.B. and Ahmed, S.M. (2015) A Review of Road Traffic Accident in Saudi Arabia: The Neglected Epidemic. Indian Journal of Forensic and Community Medicine, 2, 242-246. https://doi.org/10.5958/2394-6776.2015.00010.7

[22] Hokkam, E., Gonna, A., Zakaria, O. and El-Shemally, A. (2015) Trauma Patterns in Patients Attending the Emergency Department of Jazan General Hospital, Saudi Arabia. World Journal of Emergency Medicine, 6, 48-53. https://doi.org/10.5847/wjem.j.1920-8642.2015.01.009

[23] Alshammari, M.M., Abo El-Fetoh, N.M., Alshammari, M.S., Alshammari, A.S., Alsharari, A.M., Alshammari, O.M., Alshammari, Y.N., Alshammari, A.Z., Alshammari, A.K., Alenezi, O.T. and Alanazi, A.B. (2017) A Study on Road Traffic Accidents in Arar, Saudi Arabia. Egyptian Journal of Surgery, 36, 451-456. https://doi.org/10.4103/ejs.ejs_81_17

[24] Mansuri, F.A., Al-Zalabani, A.H., Zalat, M.M. and Qabshawi, R.I. (2015) Road Safety and Road Traffic Accidents in Saudi Arabia: A Systematic Review of Existing Evidence. Saudi Medical Journal, 36, 418-424. https://doi.org/10.15537/smj.2015.4.10003

[25] Algora-Buenafé, A.F., Suasnavas-Bermúdez, P.R., Merino-Salazar, P. and GómezGarcía, A.R. (2017) Epidemiological Study of Fatal Road Traffic Accidents in Ecuador. Australasian Medical Journal, 10, 238-245.

[26] Emara, A.M., Greiw, A.S. and Hassan, N.A. (2015) Pattern of Road Traffic Injuries in Patients Admitted to Al-jlaa Hospital, Benghazi, Libya. Tanta Medical Journal, 43, 39-45. https://doi.org/10.4103/1110-1415.158045

[27] Ziyab, A.H. and Akhtar, S. (2012) Incidence and Trend of Road Traffic Injuries and Related Deaths in Kuwait: 2000-2009. Injury, 43, 2018-2022.

https://doi.org/10.1016/j.injury.2011.09.023

[28] Seid, M., Azazh, A., Enquselassie, F. and Yisma, E. (2015) Injury Characteristics and Outcome of Road Traffic Accident among Victims at Adult Emergency Department of Tikur Anbessa Specialized Hospital, Addis Ababa, Ethiopia: A Prospective Hospital Based Study. BMC Emergency Medicine, 15, 10.

https://doi.org/10.1186/s12873-015-0035-4

[29] Lee, W.K., Lee, H.A., Hwang, S.S., Kim, H., Lim, Y.H., Hong, Y.C., et al. (2014) A Time Series Study on the Effects of Cold Temperature on Road Traffic Injuries in Seoul, Korea. Environmental Research, 132, 290-296. https://doi.org/10.1016/j.envres.2014.04.019

[30] Batstone, M.D., Monsour, F.N.T., Pattel, P. and Lynham, A. (2007) The Patterns of Facial Injury Suffered by Patients in Road Traffic Accidents: A Case Controlled Study. International Journal of Surgery, 5, 250-254. 
https://doi.org/10.1016/j.ijsu.2006.10.002

[31] Oviedo-Trespalacios, O. and Scott-Parker, B. (2017) The Sex Disparity in Risky Driving: A Survey of Colombian Young Drivers. Traffic Injury Prevention, 19, 9-17. https://doi.org/10.1080/15389588.2017.1333606

[32] Shanks, N.J., Ansari, M. and Ai-Kalai, D. (1994) Road Traffic Accidents in Saudi Arabia. Public Health, 108, 27-34. https://doi.org/10.1016/S0033-3506(05)80032-0

[33] Barrimah, I., Midhet, F. and Sharaf, F. (2012) Epidemiology of Road Traffic Injuries in Qassim Region, Saudi Arabia: Consistency of Police and Health Data. International Journal of Health Sciences, 6, 31-41. https://doi.org/10.12816/0005971

[34] Dandona, R., Kumar, G.A. and Dandona, L. (2006) Risky Behavior of Drivers of Motorized Two Wheeled Vehicles in India. Journal of Safety Research, 37, 149-158. https://doi.org/10.1016/j.jsr.2005.11.002

[35] Nantulya, V. and Reich, M. (2003) Equity Dimensions of Road Traffic Injuries in Low- and Middle-Income Countries. Injury Control and Safety Promotion, 10, 13-20. https://doi.org/10.1076/icsp.10.1.13.14116

[36] Laflamme, L. and Diderichsend, F. (2000) Social Differences in Traffic Injury Risks in Childhood and Youth-A Literature Review and a Research Agenda. Injury Prevention, 6, 293-298. https://doi.org/10.1136/ip.6.4.293

[37] Mohtasham-Amiri, Z., Dastgiri, S., Davoudi-kiakalyeh, A., Imani, A. and Mollarahimi, K. (2016) An Epidemiological Study of Road Traffic Accidents in Guilan Province, Northern Iran in 2012. Bulletin of Emergency and Trauma, 4, 230-235.

[38] Shamim, M. (2017) Pattern of Injuries from Road Traffic Accidents Presented at a Rural Teaching Institution of Karachi. Indian Journal of Surgery, 79, 332-337. https://doi.org/10.1007/s12262-017-1605-3

[39] Ibrahim, N.A., Ajani, A.W.O., Mustafa, I.A., Balogun, R.A., Oludara, M.A., Idowu, O.E. and Solagberu, B.A. (2017) Road Traffic Injury in Lagos, Nigeria: Assessing Prehospital Care. Prehospital and Disaster Medicine, 32, 424-430. https://doi.org/10.1017/S1049023X17006410 